\title{
Stresses in Composite Shafts Subjected to Unbalance Excitation and Transmitted Torque
}

\author{
H.B.H. GUBRAN, S.P. SINGH and K. GUPTA*
}

Mechanical Engineering Department, Indian Institute of Technology, Hauz Khas, New Delhi 110016, India

(Received 24 April 1998; In final form 14 August 1998)

\begin{abstract}
In the present study, stress analysis of fiber reinforced thin composite shafts subjected to unbalance excitation and steady torque, is carried out. Shafts of uniform as well as variable wall thickness are considered. The shaft is modeled as a simply supported Timoshenko beam in which shear deformation, rotary inertia and gyroscopic effects have been included. Modified equivalent modulus beam theory has been adopted. Rayleigh-Ritz displacements are used for deriving the solution equations. Shafts with a uniform wall thickness, and with variable wall thickness in which the thickness is varied along the axial length of the shaft for three different cases of fiber angles have been studied. Axial variation of stresses is studied in detail. Results obtained indicate that the stresses in the variable wall thickness are smaller than the one with uniform wall thickness, even for the same weight of the shaft.
\end{abstract}

Keywords: Composite shaft, Unbalance excitation, Stress, Tapered shaft, Torque

\begin{tabular}{|c|c|c|c|}
\hline \multicolumn{2}{|c|}{ NOMENCLATURE } & \multirow{2}{*}{$\begin{array}{l}A_{i j} \\
u, v\end{array}$} & \multirow{2}{*}{$\begin{array}{l}\text { Elements in the extensional stiffness } \\
\text { matrix } A \text { of the laminate } \\
\text { Inplane displacement in the } x \text { and } \\
\theta \text { directions }\end{array}$} \\
\hline$\varepsilon_{x x}, \varepsilon_{\theta \theta}$ & $\begin{array}{l}\text { Normal strains in the lamina } \\
\text { in } x \text { and } \theta \text { directions }\end{array}$ & & \\
\hline$\tau_{x \theta}, \gamma_{x \theta}$ & $\begin{array}{l}\text { Shear stress and strain in the } \\
\text { lamina in } x-\theta \text { plane }\end{array}$ & $w$ & $\begin{array}{l}\text { Transverse displacement along } \\
r \text { direction }\end{array}$ \\
\hline$\sigma_{x x}, \sigma_{\theta \theta}$ & $\begin{array}{l}\text { Normal stresses in the lamina } \\
\text { in } x \text { and } \theta \text { directions }\end{array}$ & $\alpha, \beta$ & $\begin{array}{l}\text { Rotations due to bending in } \\
x-z \text { and } y-z \text { planes, respectively }\end{array}$ \\
\hline$E, G$ & $\begin{array}{l}\text { Shaft longitudinal and shear } \\
\text { modulii, } \mathrm{MPa}\end{array}$ & $\bar{w}, \bar{v}$ & $\begin{array}{l}\text { Deflections in cartesian coordinates } \\
\text { (Fig. 1) }\end{array}$ \\
\hline \multirow{3}{*}{$\bar{Q}_{i j}$} & Shaft major Poission ratio & $\psi, \phi$ & The bending and rotational slopes, \\
\hline & Elements in the lamina stiffness & & respectively \\
\hline & $\begin{array}{l}\text { matrix with respect to shaft } \\
\text { geometric axes. }\end{array}$ & $z$ & $\begin{array}{l}\text { Distance to the } i \text { th lamina from } \\
\text { the mid-plane, } \mathrm{m}\end{array}$ \\
\hline
\end{tabular}

* Tel.: 0091-11-6861977. Ext. 3166. Fax: 0091-11-6362037. E-mail: kgupta@mech.iitd.ernet.in. 


\begin{tabular}{|c|c|}
\hline$r_{\mathrm{m}}$ & Mean radius of the shaft, $\mathrm{m}$ \\
\hline$t_{i}, t$ & $\begin{array}{l}\text { Thickness of the } i \text { th lamina and } \\
\text { total thickness, respectively }\end{array}$ \\
\hline$\Omega$ & Whirl frequency \\
\hline$\omega$ & Critical speed of the shaft \\
\hline$\rho$ & Shaft material density, $\mathrm{kg} / \mathrm{m}^{3}$ \\
\hline$[M]$ & Shaft mass matrix \\
\hline$[K]$ & Shaft stiffness matrix \\
\hline$M_{\mathrm{D} i}$ & Mass of $i$ th disk \\
\hline I & $\begin{array}{l}\text { Second area moment of shaft } \\
\text { cross-section }\end{array}$ \\
\hline$I_{\mathrm{DT} i}, I_{\mathrm{DP} i}$ & $\begin{array}{l}\text { Lateral and polar mass moments } \\
\text { of inertia of } i \text { th disk, respectively }\end{array}$ \\
\hline$A$ & $\begin{array}{l}\text { Cross sectional area of the } \\
\text { shaft (Eq. 2) }\end{array}$ \\
\hline$u_{r}$ & The amount of unbalance, $\mathrm{kg} \mathrm{m}$ \\
\hline$x_{r}$ & Location of the unbalance mass \\
\hline$T_{\mathrm{t}}$ & Applied torque, $\mathrm{N}$ \\
\hline Subscript "," & $\begin{array}{l}\text { denotes differentiation with } \\
\text { respect to } x \text { or } \theta \text {. }\end{array}$ \\
\hline Overdot “’” & $\begin{array}{l}\text { denotes differentiation with } \\
\text { respect to time. }\end{array}$ \\
\hline
\end{tabular}

\section{INTRODUCTION}

The literature on dynamics of composite shafts deals primarily with critical speeds and unbalance response which provides only part of the information needed by the designer. Not much information is available in literature on stresses in composite shafts. Bauchau (1983) performed analytical and experimental investigations on composite shafts of uniform as well as variable wall thickness operating in the sub-critical region. His analysis included determination of shaft stiffness, strength characteristics and dynamic stresses under unbalance conditions. Darlow and Creonte (1995) further optimized the shaft by allowing the fiber layup and thickness to vary along the shaft length. Singh and Gupta (1996) have determined modal stresses in the uniform wall thickness composite shaft crosssection by a layer-wise beam theory. In the present study, unbalance response calculation has been extended to evaluate the stresses induced in the shaft. In general, unbalance may be distributed over the entire length of the shaft and induced stresses become important if the amount of unbalance is more or if the shaft is operating near one of its critical speeds. The stresses induced in the shaft due to the application of constant torque in addition to the unbalance excitation are evaluated. Axial variation of stresses, which does not seem to have been analyzed in literature for composite shafts, has been studied in detail for various cases of shafts with uniform and variable wall thickness. Present study provides a better understanding on the problem and will be useful in developing optimum designs of rotating composite shafts.

\section{METHOD OF ANALYSIS}

Rayleigh-Ritz procedure is used for eigenvalue analysis as well as the unbalance response analysis. Referring to Fig. 1, the displacement field is described by the transverse displacements $w$ and $v$ measured in the $z$ and $y$ directions, and the bending slopes $\alpha$ and $\beta$ in $x-z$ and $x-y$ planes. The quantities $w, v, \alpha$ and $\beta$ are assumed to be time dependent and can be represented as

$$
w=\bar{w} \mathrm{e}^{\mathrm{i} \Omega t}, \quad v=\bar{v} \mathrm{e}^{\mathrm{i} \Omega t}, \quad \alpha=\bar{\alpha} \mathrm{e}^{\mathrm{i} \Omega t}, \quad \beta=\bar{\beta} \mathrm{e}^{\mathrm{i} \Omega t},
$$

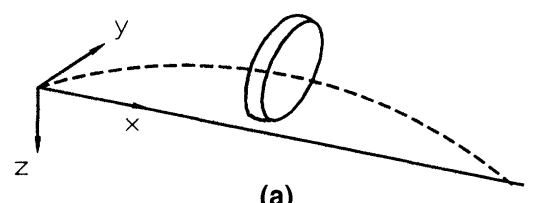

(a)
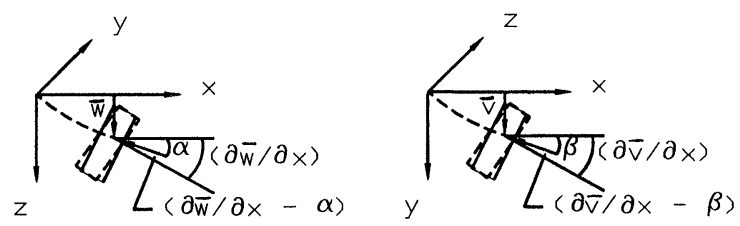

(b)

FIGURE 1 (a) Coordinate system of the rotor, (b) displacement field in cartesian coordinates. 
where $\Omega$ is the whirl frequency. The kinetic and strain energies of the system are determined. The total kinetic energy is the sum of the kinetic energies of the shaft and of the discs mounted on it. This can be expressed as

$$
\begin{aligned}
T= & \frac{\rho A}{2} \int_{0}^{l}\left(\dot{w}^{2}+\dot{v}^{2}\right) \mathrm{d} x \\
& +\frac{\rho I}{2} \int_{0}^{l}\left(\dot{\alpha}^{2}+\dot{\beta}^{2}\right) \mathrm{d} x+2 \rho I \omega \int_{0}^{l} \dot{\alpha} \beta \mathrm{d} x \\
& +\sum_{i=1}^{N D}\left[\frac{1}{2} M_{\mathrm{D} i}\left(\dot{w}\left(x_{i}\right)^{2}+\dot{v}\left(x_{i}\right)^{2}\right)\right. \\
& \left.+\frac{1}{2} I_{\mathrm{DT} i}\left(\dot{\alpha}\left(x_{i}\right)^{2}+\dot{\beta}\left(x_{i}\right)^{2}\right)+I_{\mathrm{DP} i} \omega \dot{\alpha}\left(x_{i}\right) \beta\left(x_{i}\right)\right] .
\end{aligned}
$$

The strain energy, including the shear deformation effects, is

$$
\begin{aligned}
U= & \frac{1}{2} \int_{0}^{l}\left\{E I\left[\left(\frac{\partial \alpha}{\partial x}\right)^{2}+\left(\frac{\partial \beta}{\partial x}\right)^{2}\right]\right. \\
& \left.+K^{\prime} G A\left[\left(\frac{\partial w}{\partial x}-\alpha\right)^{2}+\left(\frac{\partial v}{\partial x}-\beta\right)^{2}\right]\right\} \mathrm{d} x,
\end{aligned}
$$

where $E$ and $G$ are the longitudinal and shear moduli of the shaft which are evaluated by using classical laminate theory taking into account shearnormal coupling effects as

$$
\begin{aligned}
& E=\left(A_{11} a-A_{12} b+A_{16} c\right) /(a t) \quad \text { and } \\
& G=\left(A_{11} a-A_{12} b+A_{16} c\right) /(f t),
\end{aligned}
$$

where

$$
\begin{aligned}
& a=A_{22} A_{66}-A_{26}^{2}, \quad b=A_{12} A_{66}-A_{16} A_{26}, \\
& c=A_{12} A_{26}-A_{16} A_{22}, \quad f=A_{11} A_{22}-A_{12}^{2},
\end{aligned}
$$

$t$ is the total thickness of the shaft and $A_{i j}$ are the elements in the extensional stiffness matrix of the shaft given by

$$
A_{i j}=\sum_{k=1}^{n} \bar{Q}(i, j, k) t_{k} .
$$

The shear correction factor $K^{\prime}$ in Eq. (3) for thin tube (Dharmarajan and McCutchen, 1973) is given by $K^{\prime}=E /(2 E-\nu G)$. The Lagrangian function can be written as $L=U-T$, where $U$ and $T$ are the magnitudes of the strain and kinetic energies respectively. The response quantities $w, v, \alpha$ and $\beta$ are assumed in a series solution as

$$
\begin{array}{ll}
\bar{w}(x)=\sum_{k=1}^{K} W_{k} \sin \frac{k \pi x}{l}, & \bar{\nu}(x)=\sum_{k=1}^{K} V_{k} \sin \frac{k \pi x}{l}, \\
\bar{\alpha}(x)=\sum_{k=1}^{K} A_{k} \cos \frac{k \pi x}{l}, & \bar{\beta}(x)=\sum_{k=1}^{K} B_{k} \cos \frac{k \pi x}{l} .
\end{array}
$$

The solution equations are obtained by setting $L$ stationary with respect to the solution coefficients. On setting the derivatives of $L$ equal to zero, i.e.,

$$
\begin{aligned}
& \partial L / \partial W_{k}=0, \quad \partial L / \partial V_{k}=0 \\
& \partial L / \partial A_{k}=0, \quad \partial L / \partial B_{k}=0
\end{aligned}
$$

the time dependence cancels out in all the terms. A set of $4 K$ simultaneous algebraic equations in the form of a quadratic eigenvalue problem is obtained as

$$
\left[-\Omega^{2}[M]+\mathrm{i} \Omega[D]+[K]\right]\{X\}=0
$$

where the matrix $[\mathrm{D}]$ involves the contribution due to gyroscopic effect and is dependent on rotational speed $\omega$.

\section{Unbalance Response Formulation}

Generally, the unbalance is distributed over the entire length of the shaft. However, in the present analysis the unbalance is assumed at the mass location. A mass $m_{r}$ with eccentricity $e_{r}$ and phase angle $\phi_{r}$ gives rise to unbalance $u_{r}$, which can be represented as $u_{r}=m_{r} e_{r} \angle \phi_{r}$. The total kinetic energy of all unbalance masses can be represented as

$$
T_{u}=\omega \sum_{r} u_{r} \mathrm{e}^{\mathrm{i} \phi_{r}}\left[\dot{\bar{v}}\left(x_{r}\right)-\mathrm{i} \dot{\bar{w}}\left(x_{r}\right)\right] \mathrm{e}^{\mathrm{i} \omega t},
$$


where $w\left(x_{r}\right)$ and $v\left(x_{r}\right)$ are the displacements of the rotor at location of unbalance $x=x_{r}$, and $u_{r}$ and $\phi_{r}$ are magnitude and phase (angular location) of unbalance respectively. Equation (6) can now be written as

$$
\left[-\omega^{2}[M]+i \omega[D]+[K]\right]\{X\}=\{F\}
$$

The unbalance response is obtained from the solution of the simultaneous algebraic equations, which give the unknown coefficients in Eq. (4), through the solution vector

$$
\begin{aligned}
\{X\}= & {\left[W_{1}, W_{2}, \ldots, W_{k} \quad V_{1}, V_{2}, \ldots, V_{k}\right.} \\
& \left.A_{1}, A_{2}, \ldots, A_{k} \quad B_{1}, B_{2}, \ldots, B_{k}\right]^{\mathrm{T}}
\end{aligned}
$$

Substituting the coefficients from the vector $\{X\}$ in Eq. (4), we obtain the displacement field $v, w, \alpha$ and $\beta$ in cartesian coordinates of Fig. 1. Displacement field in polar coordinates (refer Fig. 2) Eq. (5) is obtained by transformation from cartesian to polar coordinates as

$$
\begin{aligned}
u(x, \theta, z) & =-(r+z)(\alpha(x) \cos \theta+\beta(x) \sin \theta), \\
v(x, \theta, z) & =\bar{v}(x) \cos \theta-\bar{w}(x) \sin \theta, \\
w(x, \theta, z) & =\bar{w}(x) \cos \theta+\bar{v}(x) \sin \theta .
\end{aligned}
$$

In Eq. (9) $u, v, w$ on LHS denote displacements in $x$, $\theta, r$ coordinates, respectively, while $\bar{v}$ and $\bar{w}$ on RHS denote displacements in cartesian coordinates as shown in Fig. 1. The strain-displacement relations for thin shell are (Singh and Gupta, 1996)

$$
\begin{gathered}
\varepsilon_{x x}=u_{, x}, \quad \varepsilon_{\theta \theta}=\left(w+v_{, \theta}\right) /(r+z), \\
\gamma_{x \theta}=v_{, x}+u_{, \theta} /(r+z), \\
\gamma_{x z}=\psi+w_{, x}, \quad \gamma_{\theta z}=\phi+\left(w_{, \theta}-v\right) /(r+z),
\end{gathered}
$$

where $\psi$ is the bending slope given by $(\alpha \cos \theta+$ $\beta \sin \theta)$, and $\phi$ is the rotational slope assumed to be zero. Substituting the expressions for $u, v, w, \psi$ and $\phi$, the strains in the tubular shaft at any location can be calculated. The stresses are obtained in $k$ th

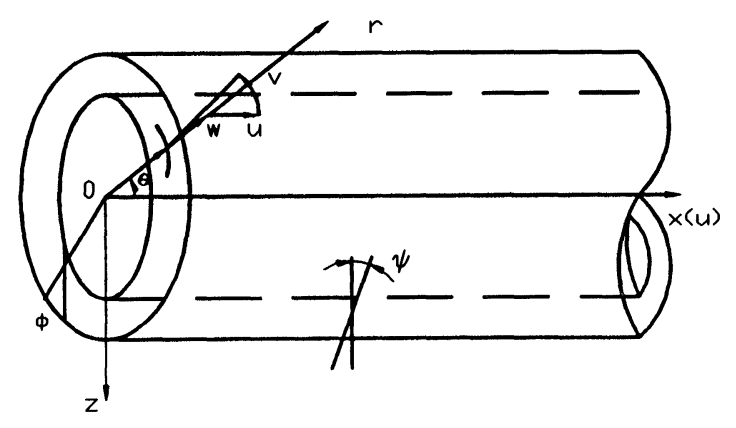

FIGURE 2 Displacement field in cylindrical coordinates.

ply from the stress-strain relations

$\left[\begin{array}{c}\sigma_{x x} \\ \sigma_{\theta \theta} \\ \tau_{x z} \\ \tau_{\theta z} \\ \tau_{x \theta}\end{array}\right]_{k}=\left[\begin{array}{ccccc}\bar{Q}_{11} & \bar{Q}_{12} & 0 & 0 & \bar{Q}_{16} \\ \bar{Q}_{21} & \bar{Q}_{22} & 0 & 0 & \bar{Q}_{26} \\ 0 & 0 & \bar{Q}_{44} & \bar{Q}_{45} & 0 \\ 0 & 0 & \bar{Q}_{54} & \bar{Q}_{55} & 0 \\ \bar{Q}_{61} & \bar{Q}_{62} & 0 & 0 & \bar{Q}_{66}\end{array}\right]_{k}\left[\begin{array}{c}\epsilon_{x x} \\ \epsilon_{\theta \theta} \\ \gamma_{x z} \\ \gamma_{\theta z} \\ \gamma_{x \theta}\end{array}\right]_{k}$

The stresses induced by the transmitted torque are evaluated separately by determining the shear strain $\gamma_{x \theta}=T_{\mathrm{t}} /\left(2 \pi r_{\mathrm{m}}^{2} t G\right)$, and then using stress strain relation [11]. The total stresses are then calculated by superimposing the stresses due to the unbalance response and transmitted torque.

\section{RESULTS AND DISCUSSION}

A graphite/epoxy shaft simply supported on rigid bearings with a disc mounted at its mid-span is studied. The shaft geometrical properties are, length $1 \mathrm{~m}$, mean diameter $100 \mathrm{~mm}$, and the ply thickness of $0.1 \mathrm{~mm}$. The mass of the disc is $7 \mathrm{~kg}$ and lateral and polar mass moments of inertia are 0.013 and $0.026 \mathrm{~kg} \mathrm{~m}^{2}$, respectively. The shaft material properties are: longitudinal, transverse and shear modulii of 130,10 and $7 \mathrm{Gpa}$, respectively, major Poissions ratio of 0.25 , and density of $1500 \mathrm{~kg} / \mathrm{m}^{3}$. The total amount of unbalance of $0.01 \mathrm{~kg} \mathrm{~cm}$ located at the same position of the disc, i.e, at the mid-span of the shaft is taken. The shaft with a uniform wall thickness has 4 base plies, and 2 outer 
plies. In the variable wall thickness shaft, the base plies are kept fixed while the outer plies are varied. In the present paper three different cases similar to those presented by Bauchau (1983) of outer plies of $\theta=0^{\circ}, 15^{\circ}$ and $30^{\circ}$ are studied. The base plies are chosen to be of $45^{\circ}$ as it provides maximum torsional strength. The thickness of the outer plies is allowed to vary along the axial length of the shaft, and the axial symmetry about the mid-plane is assumed. The shaft weight is kept the same in both cases. The profile of the shaft and the configuration of different cases are given in Fig. 3.

\subsection{Critical Speed Analysis}

Results for the first critical speed for the three different cases of uniform as well as variable wall thickness are summarized in Table I. The general trends of the results are similar to those reported by Bauchau (1983). However, in the present analysis shear-normal and bending-stretching couplings were taken into account. In the variable wall
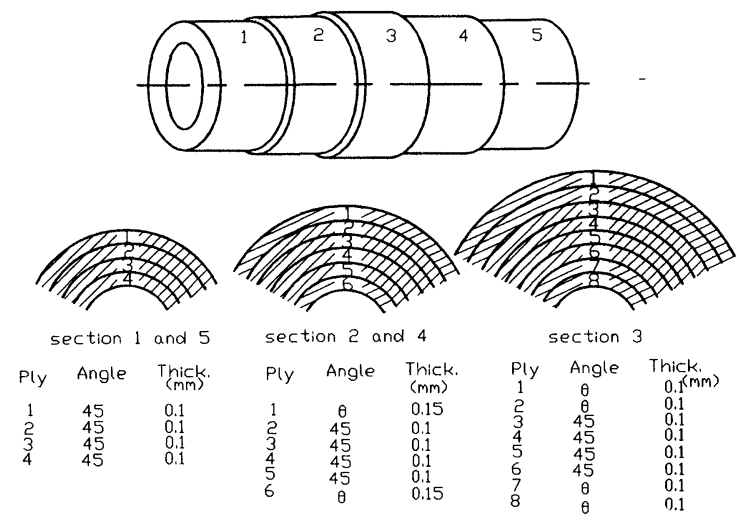

FIGURE 3 Variable wall thickness shaft configuration, $\theta=0^{\circ}, 15^{\circ}$ and $30^{\circ}$ for the cases A, B and C, respectively.

TABLE I Effect of tapering on natural frequencies, frequencies in $(\mathrm{Hz})$

\begin{tabular}{lccc}
\hline Case & Uniform thickness & Variable thickness & $\Delta \%$ (increase) \\
\hline A & 44 & 51.5 & 17 \\
B & 36 & 42 & 16.7 \\
C & 28.5 & 32 & 12.3 \\
\hline
\end{tabular}

thickness case, the natural frequency increases significantly, i.e, $12 \%$ to $17 \%$ as shown in Table I. A greater increase in the natural frequency can be obtained by optimizing the number of segments and the thicknesses along the axial length. However, in the present study, the number of segments were selected to be 5 .

\subsection{Stress Analysis}

Stresses along the axial length of the shaft as well as in plies at different locations due to unbalance excitation and transmitted torque are evaluated and compared in shafts with uniform and variable wall thickness for the three cases described in Fig. 3.

\subsubsection{Stresses due to Unbalance Excitation}

Comparison of stresses in a dynamic situation where system natural frequencies vary, requires careful considerations. The present study gives a comparative evaluation of the maximum stresses developed in shafts subjected to steady state response due to point harmonic excitation at the mid-span.The shaft executed forward synchronous circular whirl. In such a case the stresses induced at any point on the periphery of the shaft will remain the same; however, different points at different locations along the shaft periphery will have different stresses. For a comparative evaluation the shafts corresponding to the cases A, B and C with uniform and variable wall thickness, three different criteria were considered in the present analysis. In the first, a fixed amplitude of $500 \mu \mathrm{m}$ is predefined on the response plots shown in Fig. 4(a)(c), and the corresponding speeds for the uniform and variable wall thickness shafts are found from the individual plots for the cases A, B and C. The shafts are operated each at its particular speed corresponding to the response of $500 \mu \mathrm{m}$, due to unbalance excitation and the stresses induced in each shaft are evaluated. In the second, each shaft of the uniform and variable wall thickness of the cases A, B and C is operated at $10 \%$ below its first critical speed. Stresses are evaluated in each shaft 
at these speeds. Unbalance is assumed to be the same in all cases. In the third criterion, the uniform and the variable wall thickness shaft of each of the cases A, B and C are operated at the same speed which is $10 \%$ below the critical speed of the uniform shaft of the particular case. Results on the basis of second and third criteria for the cases A, B and C with unbalance excitation (U) and unbalance
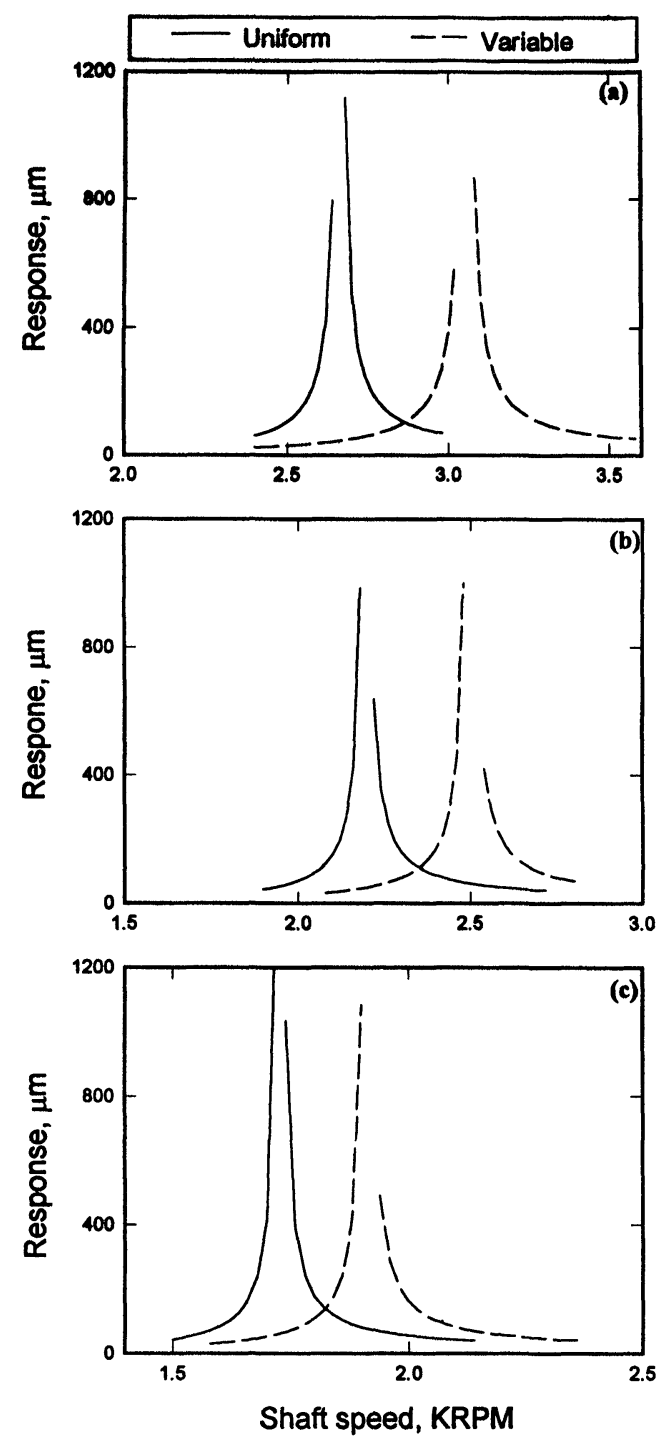

FIGURE 4 Response vs speed: (a) case A, (b) case B and (c) case $\mathrm{C}$. excitation and transmitted torque $(\mathrm{U}+\mathrm{T})$ are presented in Figs. 5 and 6.

Results on the basis of second and third criteria are shown in Fig. 5(a)-(d). Figure 5(a) shows the stresses induced in the outer ply of case $A\left(0^{\circ}\right.$ ply angle) along the axial length of the shaft. However, as this ply does not exit at the end segment of the variable wall thickness shaft, the stress distributions are shown only at the middle part. The nature of the stress distributions can be explained from the fact that there is no coupling present in the $0^{\circ}$ ply, i.e., the normal and shear stresses are uncoupled. The normal stresses $\sigma_{x x}$ and $\sigma_{\theta \theta}$ attain a maximum value at the mid-span, and a minimum value at the shaft ends. The shear stress is maximum at the ends and becomes zero at the mid-span. Results of the same case also show that the stresses induced in the variable wall thickness shaft are smaller compared to the stresses in the shaft of the uniform wall thickness. However, the stresses are much less if the variable wall thickness shaft is operated at the same speed as the uniform wall thickness shaft (dotted lines in Fig. 5(a)).

Results for case A show that the maximum stress induced at mid-span of the variable shaft operated at the same speed as the uniform shaft (third criterion) is reduced by about $61 \%$. However, this percentage is decreased to $3 \%$ if the variable shaft is operated at $10 \%$ below its first critical (second criterion). Variable shafts corresponding to the cases $\mathrm{B}$ and $\mathrm{C}$ show a reduction in the maximum stresses by about $61 \%$ and $55 \%$ for the third criterion and by $1 \%$ for the second criterion. The reduction in the maximum stresses induced in the variable wall thickness shaft for the second criterion can be explained by the increase of the shaft stiffness as a result of increasing the shaft wall thickness at the middle segment. However, the reduction of maximum stress in the variable wall thickness shaft corresponding to the third criterion is due to increase in the shaft stiffness as well as due to increase in separation margin from the shaft first critical speed.

Observations made from Fig. 5(b) and 5(c) are similar to that of case $\mathrm{A}$, except that the normal 

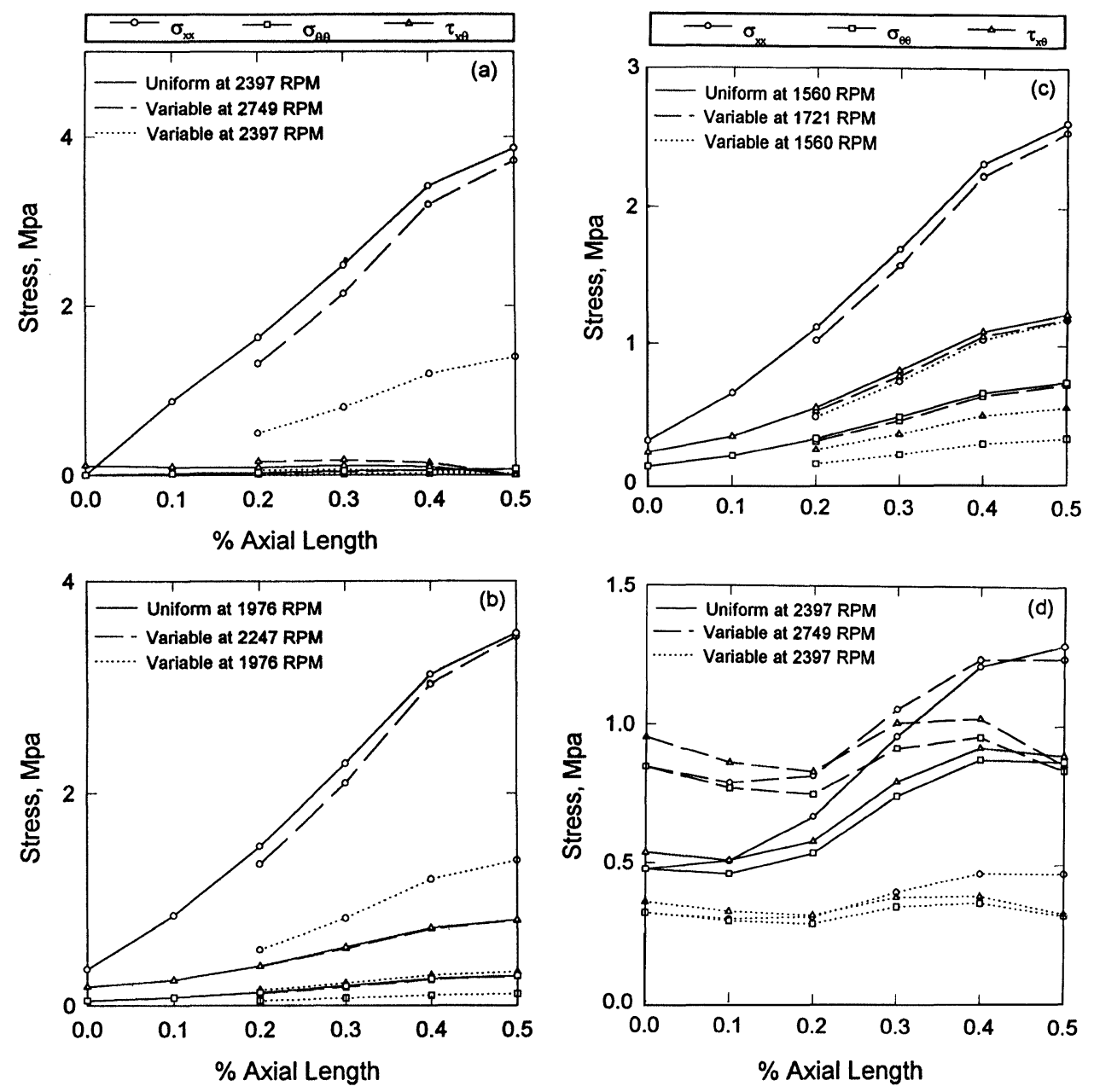

FIGURE 5 Variation of stresses induced in the shaft due to unbalance excitation along the axial length, (a) case A, (b) case B, (c) case $\mathrm{C}$ and (d) base ply of case $\mathrm{A}$.

stress $\sigma_{x x}$ and $\sigma_{\theta \theta}$ at the ends of the shaft are not zero. This can be explained as follows. Since shear stress is not zero at the shaft ends, coupling mechanism present in outer plies of cases B and C, i.e., the $15^{\circ}$ and $30^{\circ}$ plies, respectively, produces normal stresses, which is not the case in $0^{\circ}$ ply of case A. The magnitude of the stresses at end of the shaft depends on the degree of coupling mechanism present in that particular ply. This is clear from Fig. 5(d), where the stresses induced in the base ply $\left(45^{\circ}\right)$ for case $\mathrm{A}$ has been plotted. The stresses at the end of the variable shaft corresponding to the second criterion are maximum compared to the case of uniform shaft at the same location. This can be explained by the amount of coupling present in the $45^{\circ}$ ply. Results also show that fiber angle orientations strongly influence the stresses induced in the shaft. Circumferential stress increases as the fiber angle shifts from $0^{\circ}$ ply angle to $45^{\circ}$ ply angle. In general, the stresses induced in the variable wall thickness shaft operating at the same speed of the uniform wall thickness shaft (third criterion) become smaller and uniform throughout the axial length. 

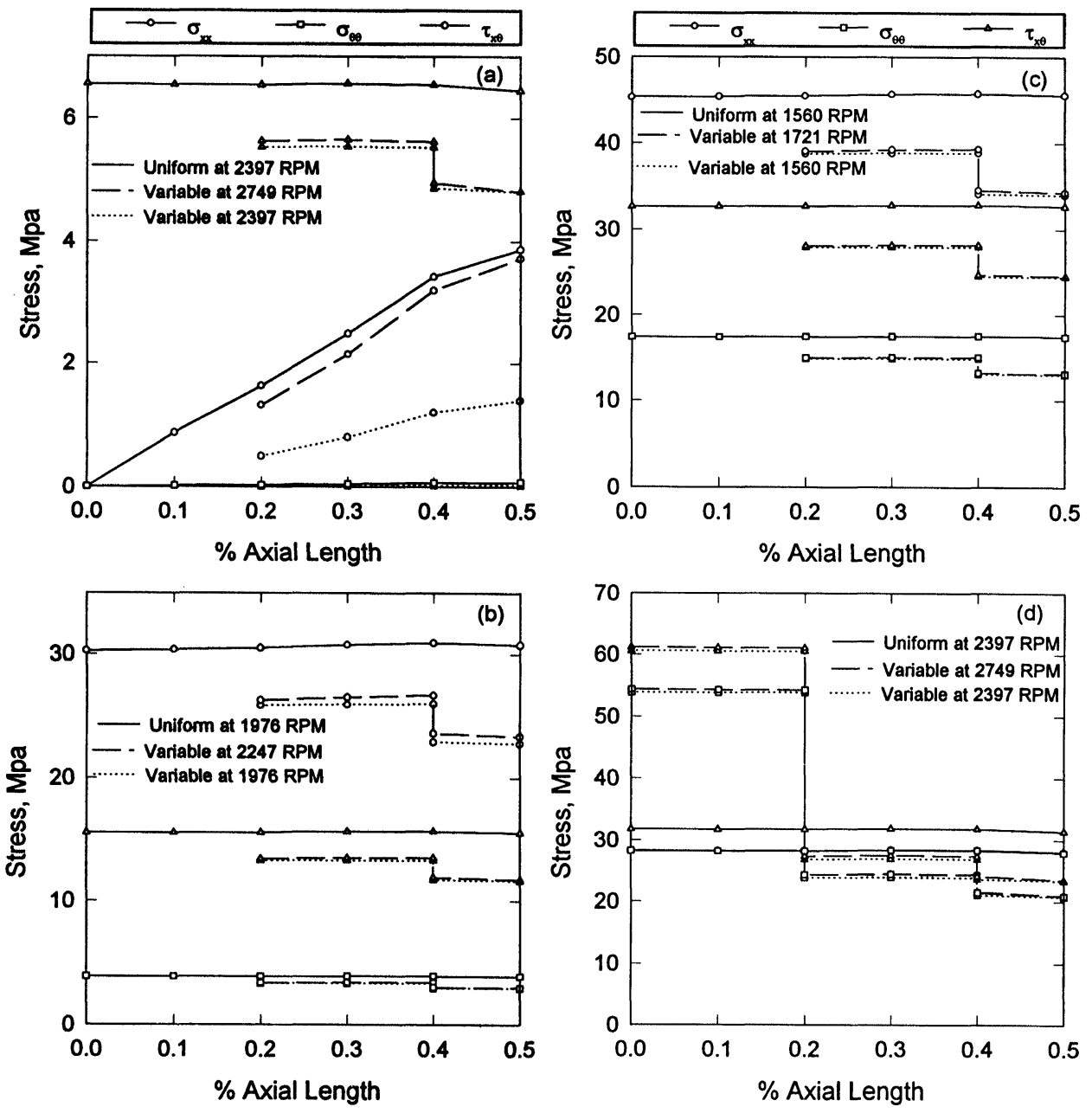

FIGURE 6 Variation of stresses induced in the shaft due to unbalance excitation and transmitted torque along the axial length: (a) case A, (b) case B, (c) case C and (d) base ply of case A.

\subsubsection{Stresses Induced due to Unbalance Excitation and Transmitted Torque}

A steady torque of $100 \mathrm{Nm}$ is applied to the shaft, and stresses induced in different plies for uniform and variable wall thickness shafts are evaluated. In general a transmitted steady torque induces shear stress only in metallic shafts; however, the case here is different. For a composite shaft transmitting a certain amount of steady torque, the shear strain induced in the shaft gives rise to normal stresses which are dependent on the coupling mechanisms present in a particular ply. In the present analysis, the stresses induced due to unbalance excitation and transmitted torque for the same cases of Fig. 5(a)-(d) are superimposed. In $0^{\circ}$ ply angles the applied torque does not produce any stresses in the fiber direction or perpendicular to the fiber direction. However, this is not the case for other ply angles. In Fig. 6(a) the normal stress $\left(\sigma_{x x}\right.$ and $\left.\sigma_{\theta \theta}\right)$ induced in the outer ply of case $\mathrm{A}\left(0^{\circ} \mathrm{ply}\right)$ remains the same as that of case $\mathrm{A}$ due to unbalance excitation only (Fig. 5(a)). However, in the presence of coupling, i.e., cases B, C and base ply of case A (Fig. 6(b)-(d)), the normal stresses $\left(\sigma_{x x}\right.$ and $\left.\sigma_{\theta \theta}\right)$ induced in the outer plies increase. In Fig. 6(d) the stresses induced in the base ply at the shaft ends of the variable shaft corresponding to case $\mathrm{A}$ are more than that of the uniform shaft. This can be explained from the fact 
that in this case, i.e., for $45^{\circ}$ ply angle, the shear stress is maximum and the coupling mechanism is strongest.

In Fig. 6(a)-(d) the stress discontinuities at the location of the change in the cross-section of the variable wall thickness shaft are observed. This can be explained due to the change in the value of shear modulus $G$ at that particular location.

\subsubsection{Interlaminar Stresses Induced due to Unbalance Excitation and Transmitted Torque}

The interlaminar stresses induced in the shaft crosssection at the mid-span due to unbalance excitation and transmitted torque for the case A are shown in Fig. 7(a) and (b). The uniform and variable wall thickness shafts are operating at $2397 \mathrm{rpm}$.

Results of Fig. 7(a) show that for a $0^{\circ}$ ply and shaft subjected to unbalance excitation only, there is no shear stress at the mid-span. Application of steady torque gives rise to shear stress, while the normal stresses remain unaffected (Fig. 7(b)). Observations for the base plies $45^{\circ}$ are different, in which the application of a steady torque is found to increase the shear stress as well as the normal stress. It is seen (Fig. 6(d)) that the amount of increase in the values of both normal stresses $\left(\sigma_{x x}\right.$ and $\left.\sigma_{\theta \theta}\right)$ is same. The above observations can be explained by the presence of coupling mechanisms $\left(\bar{Q}_{16}=\bar{Q}_{26}\right)$ in Eq. (11) in the $45^{\circ}$ ply, and by their absence $\left(\bar{Q}_{16}=\bar{Q}_{26}=0\right)$ in the $0^{\circ} \mathrm{ply}$. In general we observe that the change in circumferential stress $\left(\sigma_{\theta \theta}\right)$ is least because of torque transmission. As expected, the shear stress changes considerably and its value depends on the torque and fiber angle directions. Also in all cases the maximum stresses in variable wall thickness cases are smaller than the corresponding maximum stresses in uniform wall thickness shaft.

\section{CONCLUSION}

In this paper a simply supported composite shaft is modeled as a Timoshenko beam. The formulation takes into account rotary inertia, shear deformation
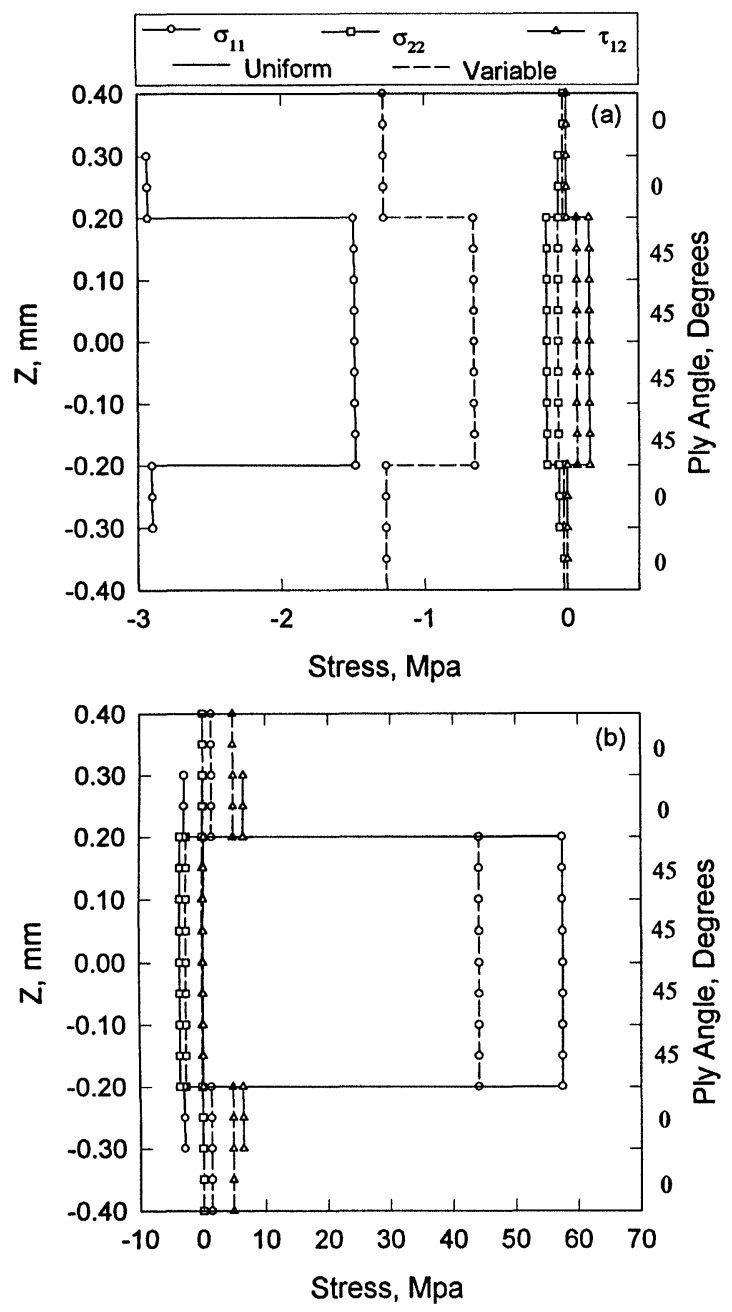

FIGURE 7 Variation of stresses across the shaft cross section at the mid-span for the uniform and variable wall thickness shaft case A at $2397 \mathrm{rpm}$ : (a) due to unbalance excitation only and (b) due to unbalance excitation and transmitted torque.

and gyroscopic effects. Three different cases (outer plies with $0^{\circ}, 15^{\circ}$ and $30^{\circ}$ ) of uniform as well as variable wall thickness shafts have been studied. Natural frequencies are evaluated including shearnormal coupling effects. Stresses induced in the uniform as well as variable wall thickness shafts due to unbalance excitation and steady torque are also evaluated. From the results, following conclusions are drawn.

(1) Varying the wall thickness of the shaft (as per Fig. 3) without altering the shaft mass, 
increases the natural frequency by about $12-$ $17 \%$. The modification in shaft wall thickness as per Fig. 3 has predominant effect in the first mode.

(2) The trend of variation of stresses in the axial direction is different compared to the case of metallic shafts. Except for the shear stress $\left(\tau_{x \theta}\right)$ in the in $0^{\circ}$ plies, the stresses are maximum at the mid-span and minimum at the shaft ends. This is because of coupling mechanisms present. In $0^{\circ}$ ply the variation of normal stresses $\left(\sigma_{x x}\right.$ and $\left.\sigma_{\theta \theta}\right)$ is similar to that of bending stresses in a metallic shaft.

(3) In all cases, it is observed that maximum stresses due to unbalance excitation $(U)$ and unbalance excitation and transmitted torque $(U+T)$ are less and uniform in the axial direction for the variable wall thickness case as compared to uniform wall thickness case.
Results show that the variable wall thickness design is superior to the uniform wall thickness design for both unbalance excitation and torque transmission.

\section{References}

Bauchau, O.A., 1983. Optimal design of high speed rotating graphite/epoxy shafts, Journal of Composite Materials, 17, $170-181$.

Darlow, M.S. and Creonte, J., 1995. Optimal design of composite helicopter power transmission shafts with axially varying fiber layup, J. of American Helicopter Society, 40(2), $50-56$.

Dharmarajan, S. and McCutchen, H., 1973. Shear coefficients for orthotropic beams, Journal of Composite Materials, 7, $530-535$.

Gubran, H.B.H., 1994. Optimal design of a helicopter tail rotor made of composite material, Masters Thesis. Mechanical Engineering Department, Indian Institute of Technology Delhi.

Singh, S.P. and Gupta, K., 1996. Composite shaft rotor dynamic analysis using a layer-wise theory, Journal of sound and vibration. 191(5), 739-756. 


\section{ait \\ ENERGY MATERIALS}

M A N E Y publishing

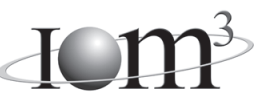

\section{Materials Science \& Engineering for Energy Systems}

Maney Publishing on behalf of the Institute of Materials, Minerals and Mining

The Institute of Materials, Minerals \& Mining

Economic and environmental factors are creating ever greater pressures for the efficient generation, transmission and use of energy. Materials developments are crucial to progress in all these areas: to innovation in design; to extending lifetime and maintenance intervals; and to successful operation in more demanding environments. Drawing together the broad community with interests in these areas, Energy Materials addresses materials needs in future energy generation, transmission, utilisation, conservation and storage. The journal covers thermal generation and gas turbines; renewable power (wind, wave, tidal, hydro, solar and geothermal); fuel cells (low and high temperature); materials issues relevant to biomass and biotechnology; nuclear power generation (fission and fusion); hydrogen generation and storage in the context of the 'hydrogen economy'; and the transmission and storage of the energy produced.

As well as publishing high-quality peer-reviewed research, Energy Materials promotes discussion of issues common to all sectors, through commissioned reviews and commentaries. The journal includes coverage of energy economics and policy, and broader social issues, since the political and legislative context influence research and investment decisions.

\section{CALL FOR PAPERS}

Contributions to the journal should be submitted online at http://ema.edmgr.com

To view the Notes for Contributors please visit: www.maney.co.uk/journals/notes/ema

Upon publication in 2006, this journal will be available via the Ingenta Connect journals service. To view free sample content online visit: www.ingentaconnect.com/content/maney

For further information please contact:

Maney Publishing UK

Tel: +44 (0)113 2497481 Fax: +44 (0)1132486983 Email: subscriptions@maney.co.uk

or

Maney Publishing North America

Tel (toll free): 8662975154 Fax: 6173546875 Email: maney@maneyusa.com

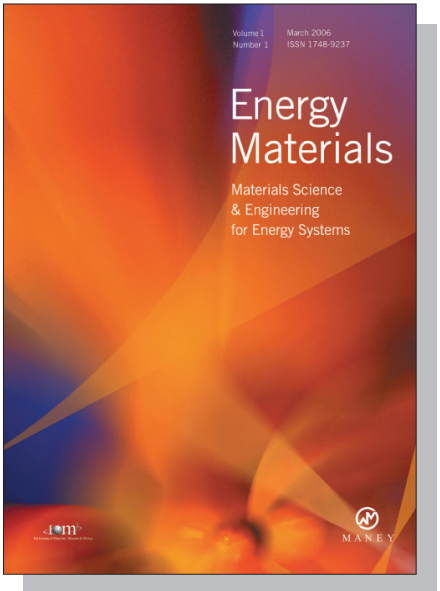

EDITORS

Dr Fujio Abe

NIMS, Japan

Dr John Hald, IPL-MPT, Technical University of Denmark, Denmark

Dr R Viswanathan, EPRI, USA

\section{SUBSCRIPTION INFORMATION}

Volume 1 (2006), 4 issues per year

Print ISSN: 1748-9237 Online ISSN: 1748-9245

Individual rate: $£ 76.00 / U S \$ 141.00$

Institutional rate: $£ 235.00 /$ US $\$ 435.00$

Online-only institutional rate: $£ 199.00 / U S \$ 367.00$

For special $\mathrm{IOM}^{3}$ member rates please email

subscriptions@maney.co.uk

\section{For further information or to subscribe online please visit www.maney.co.uk}



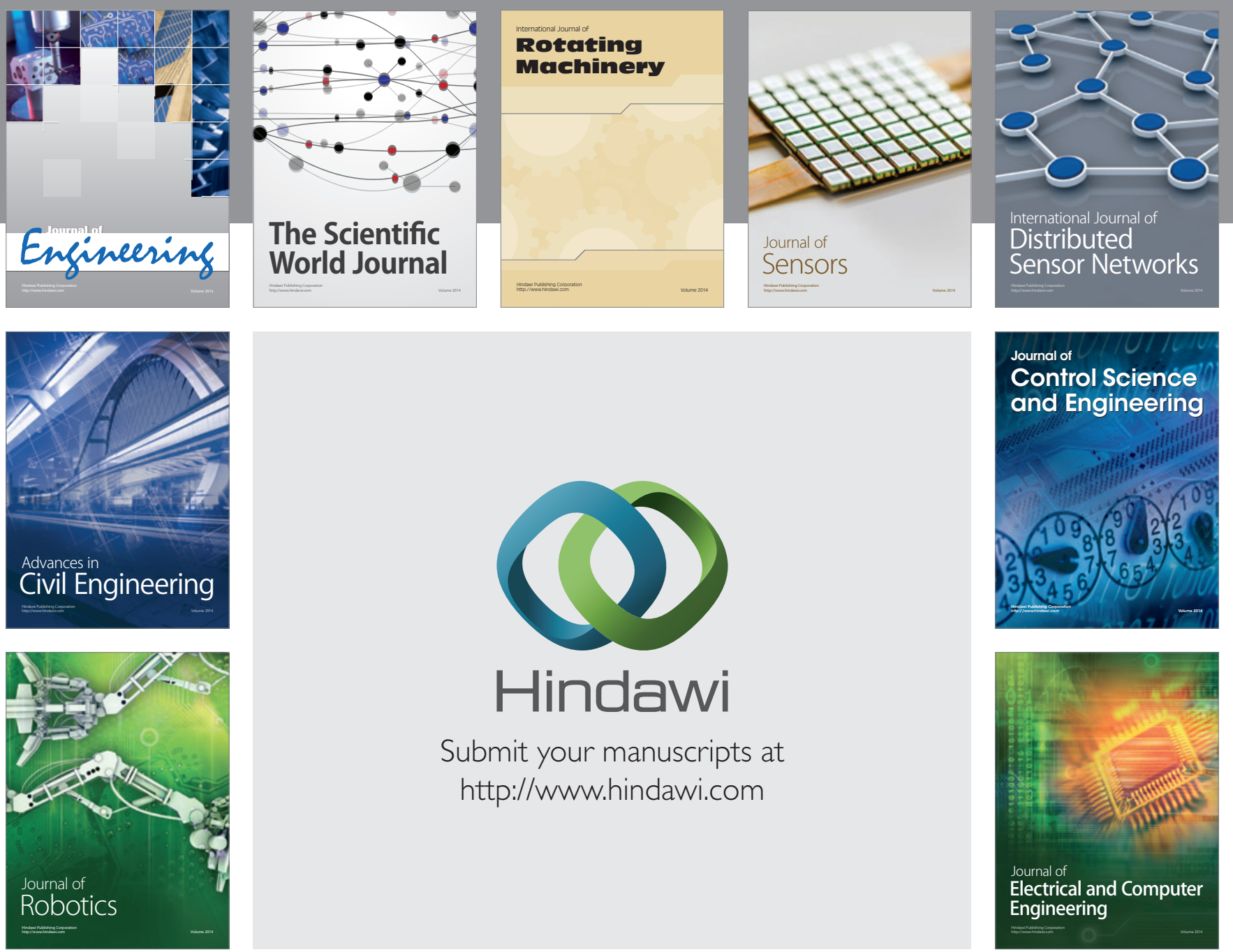

Submit your manuscripts at

http://www.hindawi.com
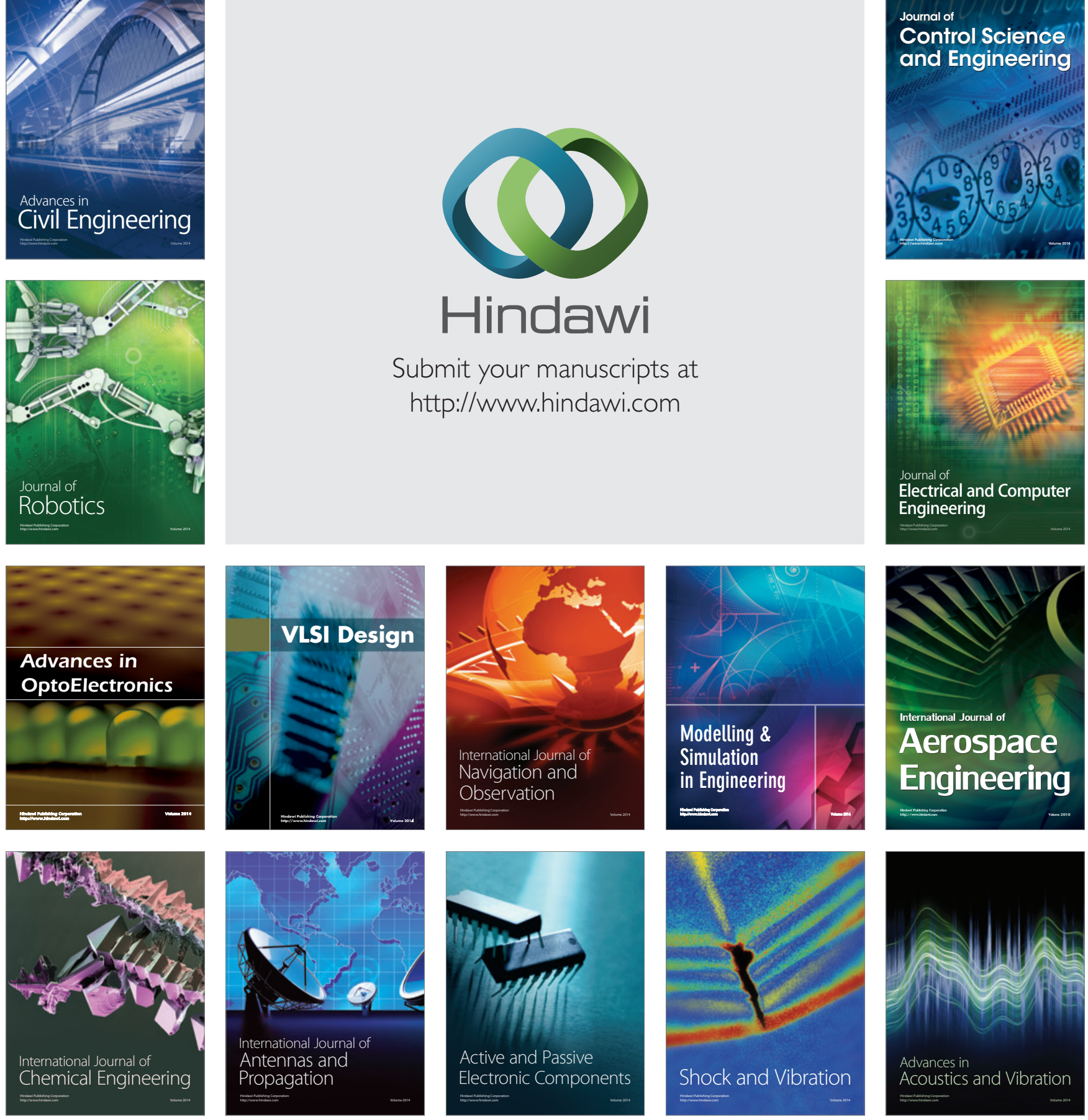